\title{
DIFFICULTIES ENCOUNTERED WHILST DRILLING AND COMPLETING DEVIATED WELLS
}

\author{
Dr. Abu Azam Md. Yassin \\ M. Eng, Ph. D. \\ Faculty of Chemical and Natural Resource Engineering. \\ Universiti Teknologi Malaysia
}

\section{Synopsis}

With the extremely high cost of developing offshore oilfield, several wells are started from a single platform and then highly deviated so that the well bottom out in the production zone in accordance with the required well spacing. The usage of highly deviated wells posed several problems relating to drilling and completing such wells. These problems and methods for elevating such problems will be discussed.

\section{Introduction}

The drilling and completing of a weil has always been one of the most crucial factors in achieving a well which will operate safely and which will produce efficiently as near as possible to its productivity potential. In offshore fields the effectiveness of the drilling and completions is of much greater importance in view of the cost involved. However, the nature of offshore oilfield development necessitates drilling and completing wells which are deviated from the vertical. This has posed severai problems in all phases of the drilling and completion operations and the major problems will be discussed.

\section{Problems of Hole Cleaning}

In highly deviated wells, there are several problems in ensuring efficient hole cleaning. Circulation in high angle well is similar to the movement of sediments in a stream bed. The bit cuttings are made up of rock fragments with a wide range of diameters (sizes). The heavier cuttings tend to drop down to the lower side of the hole due to gravity and hence resulting in the heavier cuttings and mud in the lower side, and clean mud in the upper side. The heavier cuttings and muds along the lower side of the hole moved at a slower rate than the clean mud on the upper side as shown in Figure 1.

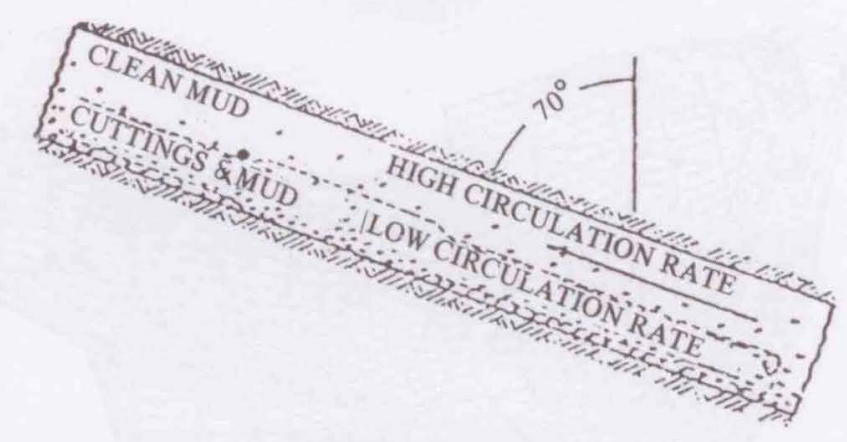

Figure 1. Circulation problem in high-angle holes.

To overcome this problem, it is necessary to use a large pump to produce the required pressure to circulate the cuttings to the surface. And also the mud properties should be carefully controlled so that the mud can carry and keep the bit cuttings in suspension.

Extensive investigations ${ }^{1,2}, 3$, has established the criteria for the selection of the proper conditions for efficient hole cleaning from vertical hole using drilling muds and little has been done on studying efficient hole cleaning from deviated wells. In field practices, a factor is added on to the conditions selected base on efficient vertical hole cleaning to allow for inefficiency due to the angle of deviation. But due to extremely high cost of developing offshore field, a 
more exact factor is needed in order to ensure optimization of drilling cost. So there is a need to investigate deviated hole cleaning to determine the exact solution to the problem.

\section{Problem of Running Casing ${ }^{4}$ and Drill Pipe}

The most common causes of pipe failure in deviated holes are extreme hole inclination (dogleg) as shown in Figure 2. In slightiy deviated holes, less than 3 degrees per 100 foot, it is not critical to consider the effects of bending on the design of pipe, especially with smaller diameter pipe. But in deviated holes of 5 degrees per 100 foot or more, however, it is necessary to take into account of the reduction in yield strength and tensile strength due to bending. When the pipe is bent, the concave side is in compression and the convex side is in tension. Both situations tend to reduce the yield and tensile strength of the pipe. In addition to the consideration of bending a pipe, additional forces is being subjected on to the couplings.

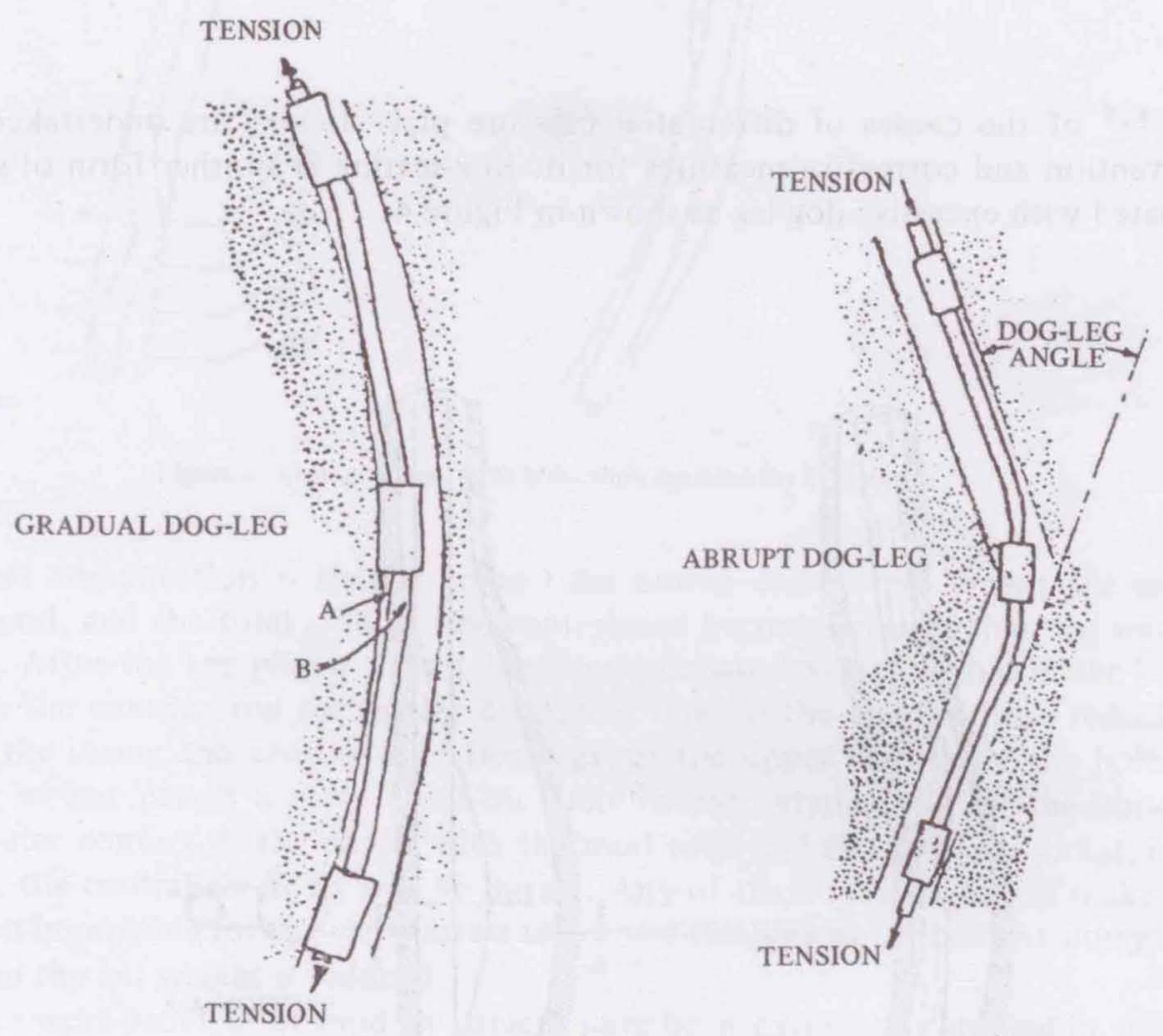

Figure 2. Drilling through dog leg exerts damaging stresses on drill pipe. Abrupt dog-leg are more damaging than gradual dog-leg.

The solution to the problem of reduction in strength due to bending stresses is to use heavier pipe through the problematic zones and to centralize the pipe throughout the critical interval.

Another problem encourtered related to pipe in deviated hole is pipe sticking. Differential pressure pipe sticking is the most common form of stuck pipe using high density muds as shown in Figure 3. 


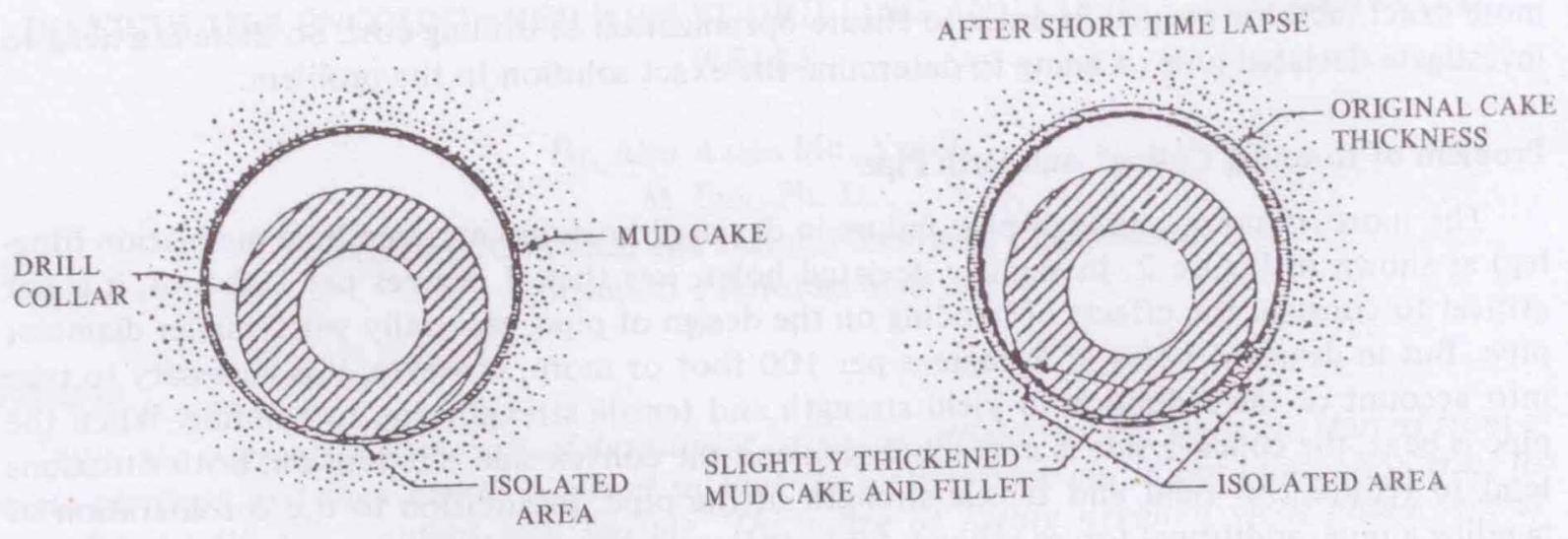

Figure 3. Stuck drill pipe results when it becomes motionless against a permeable bed. After cake buildup, hole pressure presses pipe against wall.

Investivations ${ }^{5,6}$ of the causes of differential pressure pipe sticking are undertaken so as to formulate prevention and corrective measures for it. Key-seating is another form of stuck pipe but it is associated with excessive dog-leg as shown in Figure 4.
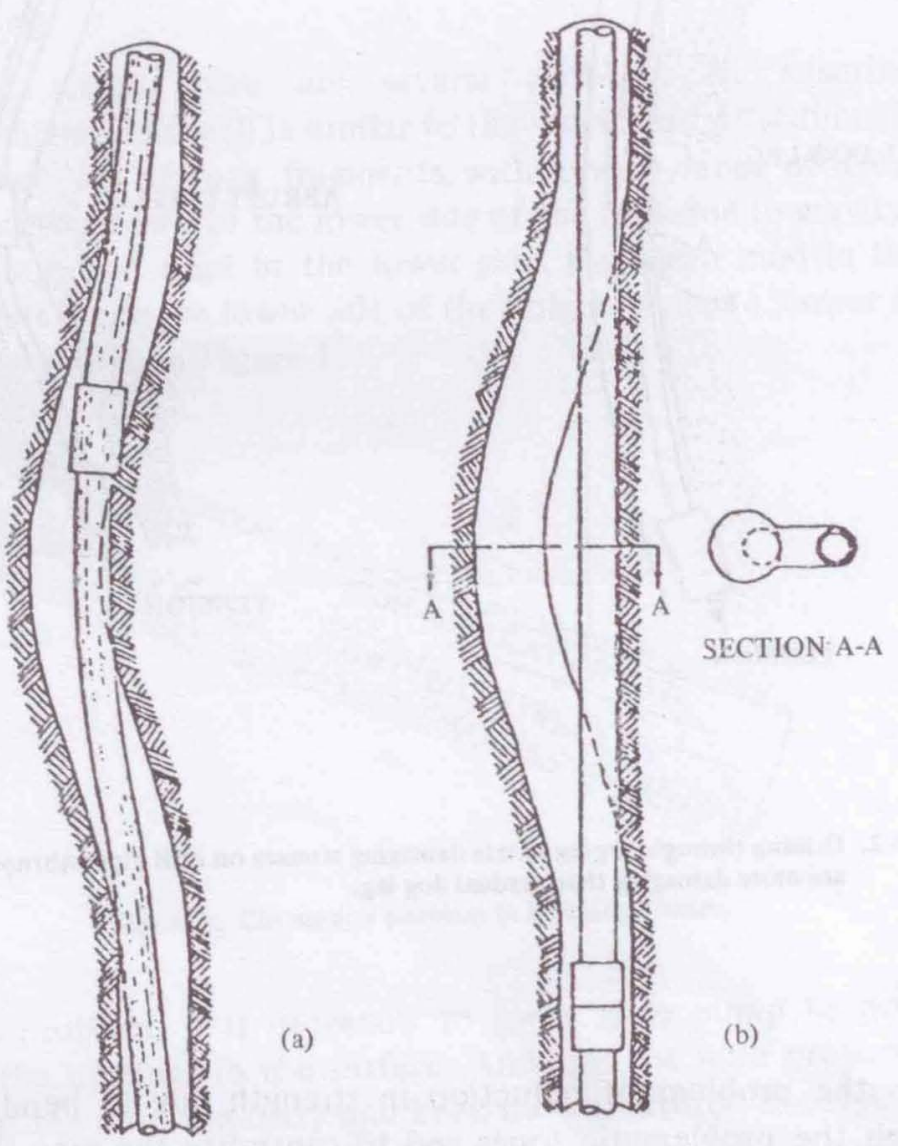

Figure 4. (a) Illustrating key seating effect on crooked hole.

(b) Position of pipe after key seating. 


\section{Problem of Cementing}

In directionally drilled holes, the casing string is forced against the wall of the hole throughout the entire interval. Even with an optimum centraliser program it is probable that the casing will be off-centred in many parts of the wellbore as shown in Figure 5. On the upper side, the resistance to flow is less, so the mud displacement is more efficient; but on the lower side, channels of mud are formed resulting in poor cementing.

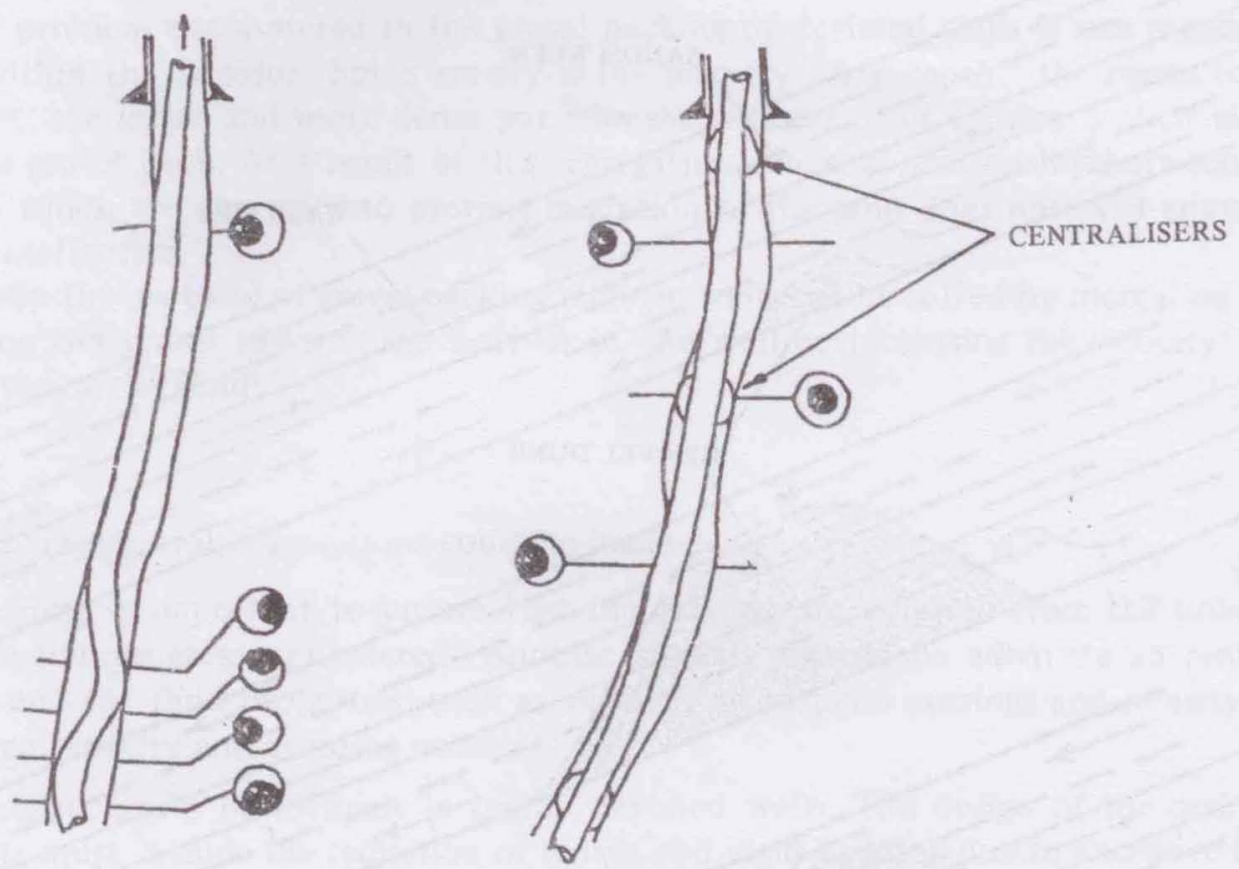

Figure 5. Casing contact with hole, showing need for centralisers.

Another complication is that at some time during cement placement the casing contains a lighter mud, and the total load on the centralizers becomes greater than the simple weight of the casing. After the top plug is placed, loading forces are reversed - that is, the heavier cement slurry is in the annulus and the lighter displacing fluid in the casing - thus reducing the actual weight of the casing and causing it to float against the upper portion of the hole. The heavier net casing weight causes a more eccentric annulus with static mud on the upper side of the casing, greater contact of the casing with the mud cake and the possibility that, in a fairly soft fcrmation, the centralizer bows will be buried. Any of these conditions will make it more difficult or even impossible for the centralizers to reenter the pipe as the cement slurry moves up the annulus and the net weight is reduced.

Displacement problem of mud by cement have been extensively studied in vertical configuration ${ }^{9,10}$ and more work is needed to understand the displacement problem associated with deviated wellbore. Apparently, the problem of cementing deviated wells can be solved by preventing channeling of cement through the mud and various techniques had been suggested ${ }^{11}$.

\section{Problem of Running Completion and Logging Tools}

The problems associated with running in tools using wireline in deviated holes are associated with friction and cable-tool weight. Extensive studies ${ }^{12,13}$ had been carried out to overcome the problems and various methods of getting the devices down were used which include extra weights, attaching to drillpipe and pumpdown tools.

Another problem is the premature set of packers in deviated holes ${ }^{14}$. When packers are not properly set, the elements have to be pulled out and redressed before running in again and this is costly in offshore operation. Mechanical devices employed to set packers also failed due to friction. Running a smooth receptacle on the casing and sting into it with a sealing element on the bottom of the tubing string alleviate the problem of premature packer setting. 


\section{Problem of Gravel Packing}

The major problem encountered in gravel packing deviated holes arises when gravel prematurely settle out near the upper end of the liner. As a result, a small gravel bank or dune, begins to form within the upper end of the annulus. Figure 6 shows the way of formation of this dune which builds towards the bottom of the hole ${ }^{15}$

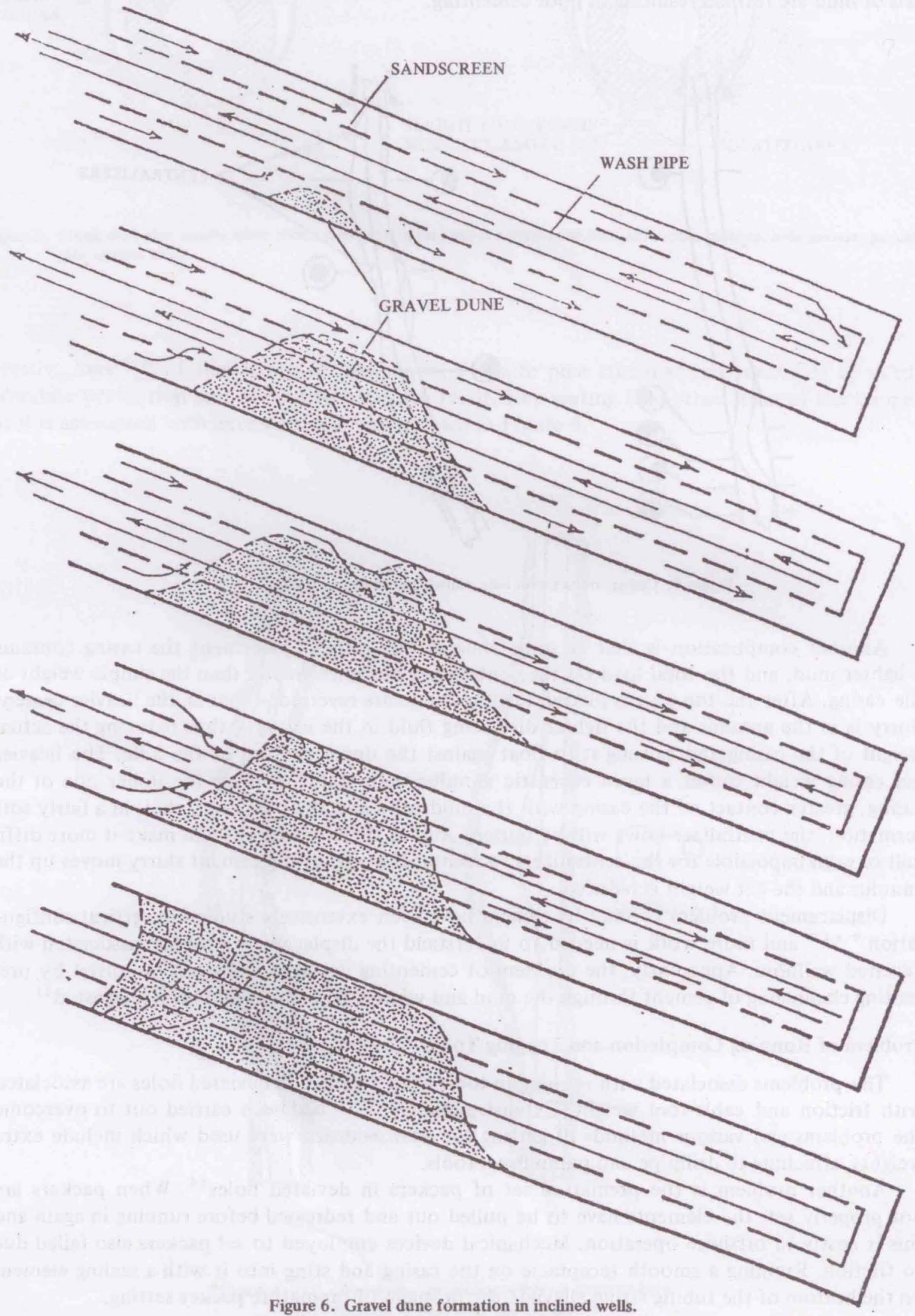


As the dune grows and descends down the annulus, more and more of the carrier liquid is diverted through the liner upstream of the dune thereby causing the velocity of the gravel suspension to decline. As the velocity drops, the carrier liquid can no longer suspend the gravel with the result that additional gravel settles out until the dune completely blocks flow to the lower portions of the annulus. Substantially all of the carrier liquid is then diverted into the upstream section of the liner causing the upper section of the annulus to pack while leaving a substantial void space in the lower section.

Another problem encountered in the gravel packing of deviated wells is size segregation of the gravel within the annulus. Since gravity is the primary force causing the gravel to form a uniform pack, the larger and more dense particles settle faster, thus causing particle size segregation in the gravel pack. As a result of this segregation, the size relationship between the formation sand which are necessary to prevent migration of the sand does not exist anymore and the gravel is ineffective.

Apparently the problem of gravel packing inclined wells can be solved by increasing the drag forces moving the gravel towards the bottom of the well by increasing the velocity ${ }^{16}$ or the viscosity of the carrier fluid ${ }^{17}$.

\section{Conclusions}

The following general observations could be made:

1. Hole cleaning is important to ensure that the cuttings are removed from the hole so that drilling could progress unhindered. Annular velocity should be adequate to remove the cuttings and the fluid properties, such as viscosity to suspend cuttings and density to provide lifting capacity and avoiding washouts.

2. Setting casing could be difficult in highly deviated wells. The design of the casing string and joints must include the reduction of tensile and yield strength due to excessive bending. Heavier pipes with buttress couplings are used for the interval where the dog-leg is greater than 3 deg per $100 \mathrm{ft}$.

3. Drilling with high-density muds is highly deviated wells leads to differential pressure sticking. Prevention of differential sticking include special treatments of drilling fluid and specially designed drilling tools. Key-seat is another problems associated with stuck pipe in excessive dog-legs.

4. Cementing deviated wells is difficult. Displacement of mud with cement requires that the mud maintain good properties. High flow rates during displacement, centralizers along critical interval, pipe movement during displacement and densified slurries with reduced water content can assist mud displacement in deviated wells.

5. Employing wireline devices and running-in packers in deviated holds could be difficult. Several modifications and pumpdown tools to overcome the gravity problem were used.

6. Gravel packing deviated wells are difficult due to segregation and imcomplete gravel placement. Using a series of flexible baffles inside the liner and high viscosity carrier fluids improve gravel placement whereas using one size gravel reduce segregation. 


\section{References}

1. ANDERSON, G.W., \& HUTCHISON, S.O., How to efficiently wash sand from deviated wells, World Oil, Dec., 1978.

2. SIFFERMAN, T.E., MYERS, G.M., HADEN, E.L., \& WAHL, H.A., Drill cutting transport in fullscale vertical annuli J. Pet. Tech., Nov., 1974.

3. WILLIAMS, C.E., d BRUCE, G.H., Carrying capacity of drilling muds. Trans. AIME, 1951.

4. WILSON, G.J., Intergrated approach to deep water North Sea drilling OTC Paper 1860 , Houston, Texas, 1972.

5. HELNICK, W.E., \& LONGLEY, A.J., Pressure differential sticking of drill pipe and how it can be avoided or relieved, Drill \& Prod. Prac., 1957.

6. ADAMS N., How to control differential pipe sticking, Part 1-4, Pet. Eng., Sept., 1977.

7. SARTAIN, B.J., Drillstem tester frees stuck pipe, Pet. Eng., Oct., 1960.

8. HOCH, R.S., How to cement high angle 'S' type directional wells Drill \& Prod. Prac., 1970.

9. Mc LEAN, P.H., MANRY, C.W., \& WHITAKER, W.W., Displacement Mechanics in primary cementing, J. Pet. Tech., Feb. 1967.

10. CARTER, L.G., COOK, C. \& SNELSON, L., Cementing research in directional gas completions, SPE 4313, London, 1973.

11. SUMAN, Jr., G.O. \& ELLIS, R.E. Cementing oil and gas wells (Part 1-6), World Oil, Aug; 1977.

12. BRATOVICH, M.W., BELL, W.T., \& KAAZ, K.D., Improved techniques for logging high angel wells, SPE 6818 Denver, Col. 1977.

13. CRIPPEN, R.G., \& WRIGHT, A.C., Procedures and techniques employed in logging and evaluating high angle wellbores on a large scale drilling and development program, Trans SPWLA, 1968.

14. ROTHOCK, Jr., R., Completing deviated wells, Pet. Eng., April 1977.

15. GRUESBECK, W.M., SALATHIEL, W.M., \& ECHOLS, E.E, Design of gravel pack in deviated wellbores, J. Pet. Tech., Jan., 1979.

16. MALY, G.P., ROBINSON, J.P. \& LAURIE, A.M., New gravel pack tool for improving pack placement, J. Pet. Tech., Jan., 1974.

17. SPARLIN, D., \& COPELAND, T., Pressure packing with concentrated gravel slurry, SPE 4033, San Antonio, Texas, 1972. 